\title{
Evaluation of Exclusive Stopping Space for Motorcycle at Signalized Intersections in Large Cities in Indonesia
}

\author{
A. Caroline Sutandi ${ }^{1, *}$, and Dennis Dwika Siregar ${ }^{1}$ \\ ${ }^{1}$ Parahyangan Catholic University, Jalan Ciumbuleuit No.94, Bandung 40141, West Java, Indonesia
}

\begin{abstract}
Proportion of motorcycles in large cities in Indonesia as a developing country is around $60 \%-71 \%$ of all vehicles and increases $19 \%$ $37 \%$ every year. Data from Indonesia Statistics Centre Bureau indicated that number of motorcycle increase from 13,563,017 in 2000 to 92,976,240 in 2014. This condition leads worse traffic congestion in large cities and more specific at signalized intersections. Motorcycles usually stop everywhere including among cars and in front of stop-line at signalized intersection during red time period. One of solutions to reduce the poor traffic congestion is implementation of exclusive stopping space (ESS) for motorcycle. Manual of ESS for motorcycle in Indonesia is used as a guidance of implementation. The aim of this study is to determine signalized intersections that need ESS for motorcycle, determine the type, and then evaluate the implementation. This study is specific, important, and crucial to do because usually exclusive stopping space in developed countries is for bicycle. Case study is carried out at all signalized intersections in large city Bandung in Indonesia. Results of study indicated that ESS for motorcycle is needed with $52.2 \%-100 \%$ effectiveness. Furthermore, recommendation that could be provided is more specific ESS guidance for existing variation of lane widths.
\end{abstract}

\section{Introduction}

Traffic congestion usually occurs in large cities in developing countries including in Indonesia. This condition is worse because number of motorcycle in the large cities in Indonesia is around $60 \%$ up to $71 \%$ of number of all vehicles and increase $19 \%$ up to $37 \%$ per year [1]. They stop everywhere among cars and even in front of stop-line at signalized intersections during red time periods. This condition blocks traffic flow from other leg intersections during next green time period. One of solutions to reduce the poor traffic congestion is implementation of exclusive stopping space (ESS) for motorcycle.

The aim of this study is to determine the signalized intersections that need ESS for motorcycle, determine the type of ESS for motorcycle, and then evaluate the implementation. This study is very specific, important, and crucial to do because usually exclusive stopping space in developed countries is for bicycles. Manual of ESS for

* Corresponding author: caroline@unpar.ac.id 
motorcycle in Indonesia is used as a guidance of implementation. Case study is carried out at all signalized intersections in large city Bandung in Indonesia. Results of this study are not only beneficial for large city Bandung and other large cities in Indonesia, but also beneficial for other large cities in other developing countries that have similar traffic and geometric conditions.

\section{Exclusive stopping space (ESS) for motorcycle}

Exclusive stopping space (ESS) for motorcycle is a space facility for motorcycle while stopping at signalized intersection during red time in large cities. The exclusive area is located between stop line at signalized intersection and stop line for vehicle with 4 wheels or more.

\subsection{Requirements for ESS for motorcycle implementation}

There are some requirements that have to be fulfilled by signalized intersections in order to implement ESS for motorcycle. The requirements are as follow [1]:

- General requirement i.e. size of signalized intersection is medium $(10 \mathrm{~m}-14 \mathrm{~m})$ and large $(>15 \mathrm{~m})[2]$.

- Geometric requirements. Each leg intersection has at least 2 lanes straight through only. Left lane for left turn on red (LTOR) in not included. A number of intersection types that fulfil the geometric requirement are presented in Fig. 1, Fig. 2, and Fig. 3. Another geometric requirement is that lane width is $3.5 \mathrm{~m}$. With this lane width, motorcycle can move among vehicles to the ESS for motorcycle. The position of motorcycles among cars is presented in Fig. 4.

- Traffic Requirements. If number of motorcycle stop at leg intersection with 2 lanes at least 30 motorcycles or at leg intersection with 3 lanes at least 45 motorcycles, during red time period, therefore ESS for motorcycle is needed. If leg intersection has more than 3 lanes, it needs ESS for motorcycle if there are at least 15 motorcycles stop during red time period. The example is presented in Table 5.

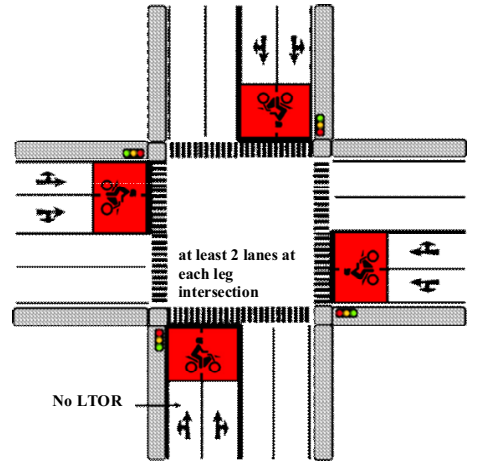

Fig. 1. Location of ESS for motorcycle at signalized intersection without LTOR and without traffic island [1]

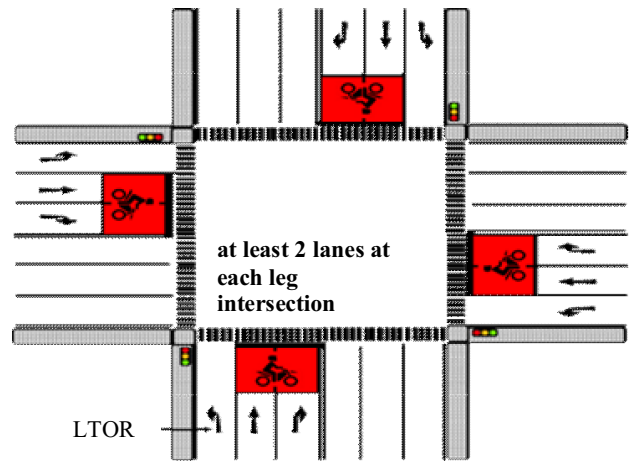

Fig. 2. Location of ESS for motorcycle at signalized intersection with LTOR and without traffic island [1] 


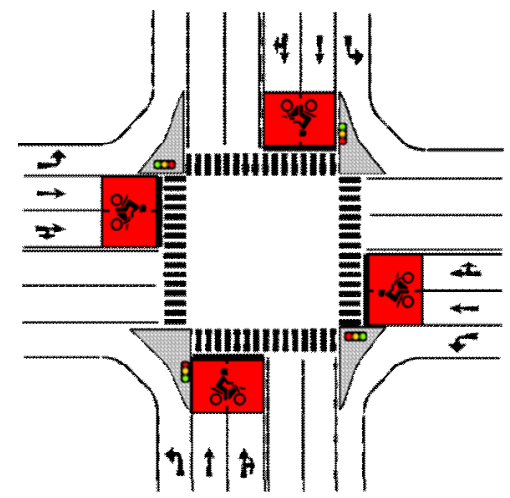

Fig. 3. Location of ESS for motorcycle at signalized intersection with LTOR and with traffic island [1]

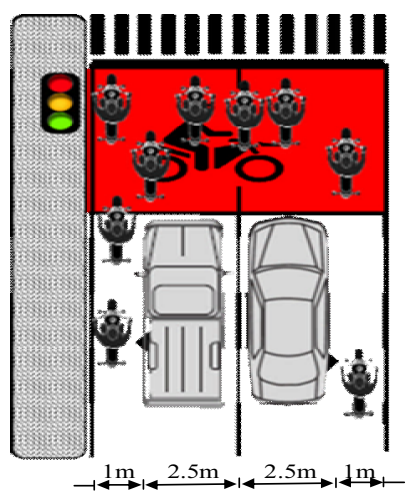

Fig. 4. The position of motorcycle among cars [1]
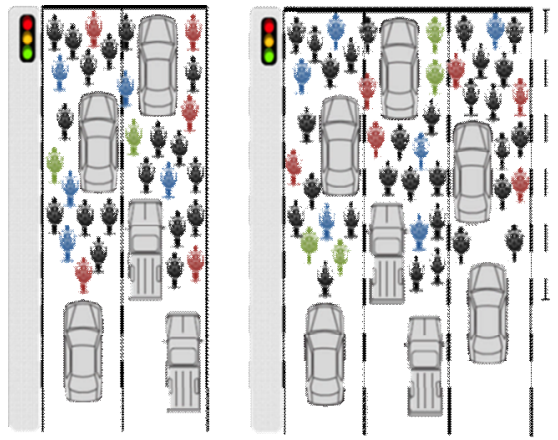

Fig. 5. Examples of leg intersections with 2 and 3 lanes that need ESS for motorcycle [1]

\subsection{Survey before implementation of ESS for motorcycle}

Before implementation of ESS for motorcycle, survey for counting the number of motorcycle at each leg intersection at each signalized intersection during red time period is needed. Steps of survey are as follow [1]:

- Survey is conducted 3 times, in the morning, at noon, and in the afternoon.

- Survey duration minimum is during 10 phases per time, so that total minimum survey duration is during 30 phases per day.

- Survey technique can be manual i.e. using traffic counter or survey form or semiautomatic using video camera.

- Summary of number of motorcycle stop at each leg intersection at signalized intersection will determine whether the leg intersection needs ESS for motorcycle or not. Furthermore, is to determine the type of ESS for motorcycle.

\subsection{Types of ESS for motorcycle}

Type of ESS for motorcycle depends on number and size of motorcycle at each leg intersection. General size of motorcycle used in Indonesia is $0.8 \mathrm{~m} \times 2.0 \mathrm{~m}\left(1.6 \mathrm{~m}^{2}\right)$, the largest kind with cylinder of $110-125 \mathrm{cc}$. Usually there is 2 types of ESS for motorcycle i.e. Square type and P type. More detail explanation is as follow [1]. 


\subsubsection{Square type of ESS for motorcycle}

Square type of ESS for motorcycle is used if number of motorcycle on each lane at leg intersection is almost the same. Length of Square type of ESS for motorcycle is between $8 \mathrm{~m}-12 \mathrm{~m}$ depend on number of motorcycle stops during red time period. While width of Square type of ESS for motorcycle is depend on the lane width. Square type of ESS for motorcycle is presented in Fig. 6.

\subsubsection{P type of ESS for motorcycle}

P type of ESS for motorcycle is used if proportion of motorcycle on left lane at leg intersection is $60 \%$ higher for leg intersection with 2 lanes and $70 \%$ higher for leg intersection with 3 lanes, than other lanes. Length of P type of ESS for motorcycle is between $12 \mathrm{~m}-16 \mathrm{~m}$ depend on number of motorcycle stops during red time period. While width of Square type of ESS for motorcycle is depend on the lane width. P type of ESS for motorcycle is also presented in Fig. 6.
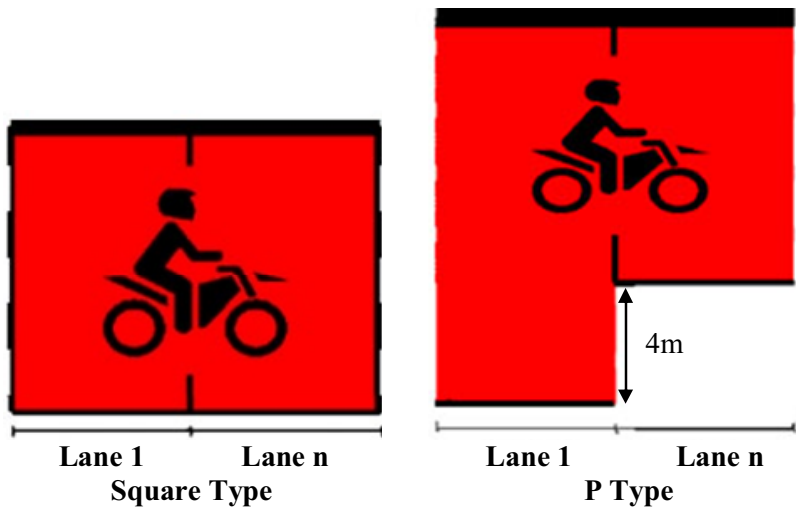

Fig. 6. Square type and P type of ESS for motorcycle [1]

\section{Methodology}

Methodology of determination, implementation, and evaluation of ESS for motorcycle in large cities in Indonesia is presented in Fig. 7. Besides manual that are used, traffic regulations also used as legal formal foundation for implementation i.e. law of Republic of Indonesia No.38 year 2004 about Road and law of Republic of Indonesia No.22 year 2009 about traffic and road transport.

\section{Data of SSE for motorcycle}

Field data is collected from all signalized intersection in large city Bandung in Indonesia. There are 87 working signalized intersections of 148 signalized intersections in Bandung. Location of the signalised intersections is presented in Fig. 8 [3, 4, 5]. 39 of 87 signalized intersections have already implemented ESS for motorcycle and will be evaluated. 48 of 87 signalized intersections have not already implemented ESS for motorcycle and will be determine whether they need implementation of ESS for motorcycle or not. 


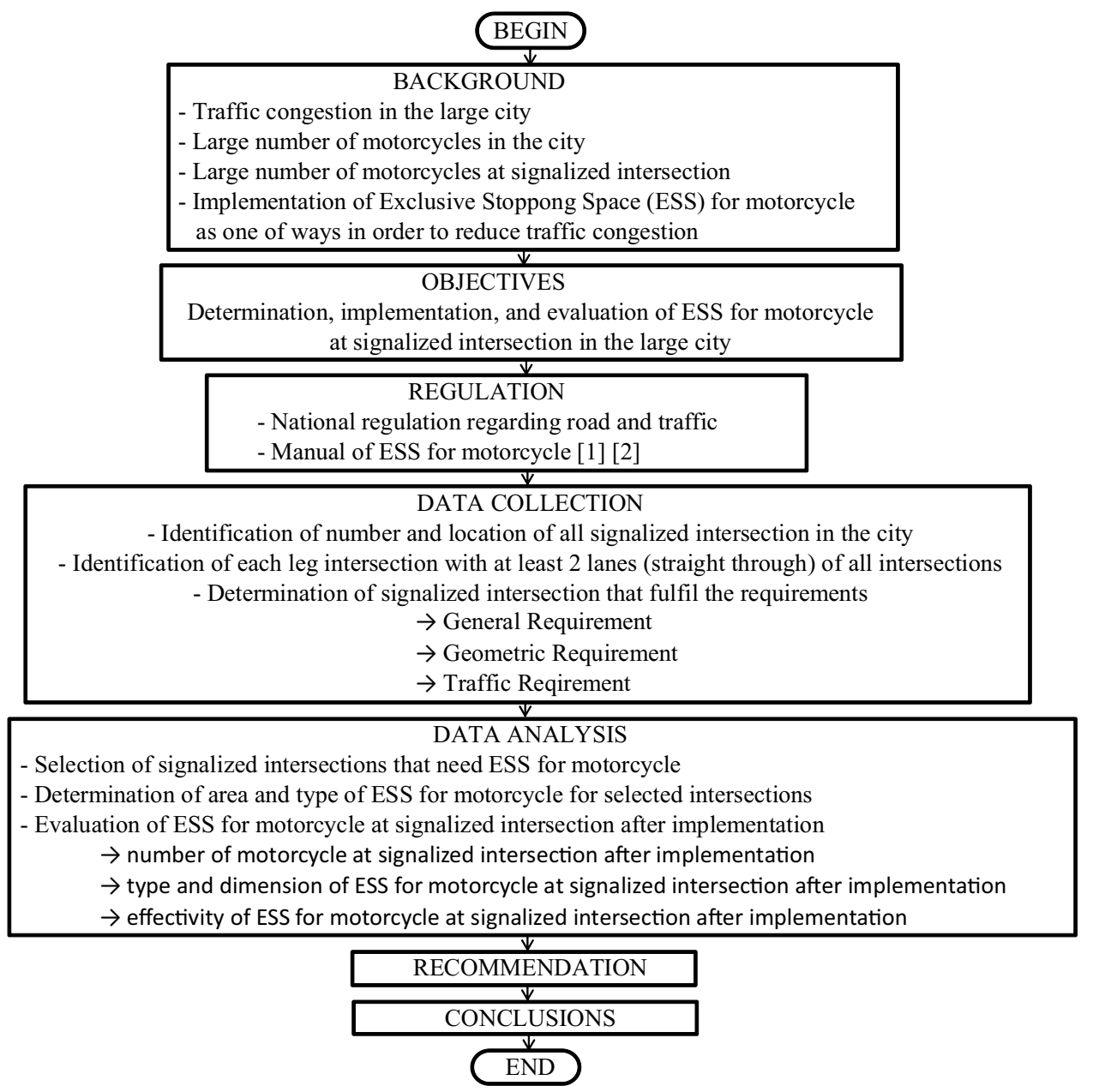

Fig. 7. Methodology of determination, implementation, and evaluation of ESS for motorcycle in large cities in Indonesia

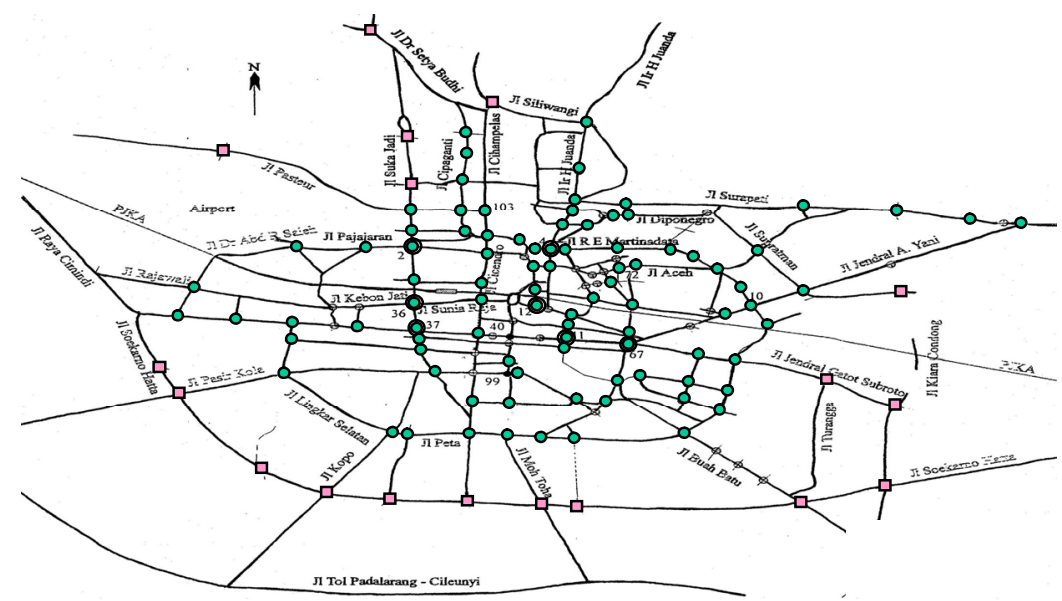

Fig. 8. Location of signalised intersections in Bandung, Indonesia $[3,4,5,6]$ 


\subsection{Determination and implementation of ESS for motorcycle}

Based on size of intersections, the 48 signalized intersections that have not already implemented ESS for motorcycle consist of 7 large intersections $(>15 \mathrm{~m}), 30$ medium intersections $(10 \mathrm{~m}-14 \mathrm{~m})$, and 11 small intersections $(6 \mathrm{~m}-9 \mathrm{~m})$.

Furthermore, signalized intersections that fulfil general requirement (large and medium intersection), geometric requirements (leg intersection with 2 straight through lanes without LTOR, and lane width is $3.5 \mathrm{~m}$ ) and traffic requirement (30 motorcycles stop at leg intersection with 2 lanes and 45 motorcycles stop at leg intersection with 3 lanes, during red time period) is only 4 intersections. Characteristics and type of ESS for motorcycle of the 4 intersections are presented in Table 1 and Fig. 9 up to Fig. 12.

Table 1. Characteristicsand type of ESS for motorcycle of the 4 intersections.

\begin{tabular}{|c|c|c|c|c|c|c|c|}
\hline \multicolumn{3}{|c|}{ Signalized Intersection } & \multicolumn{2}{|c|}{$\begin{array}{c}\text { Leg intersection that fulfil } \\
\text { all requirements }\end{array}$} & \multirow{2}{*}{$\begin{array}{c}\text { Average } \\
\text { number of } \\
\text { motorcycles } \\
\text { during red } \\
\text { time period }\end{array}$} & \multirow{2}{*}{$\begin{array}{c}\text { Proportion } \\
\text { of } \\
\text { motorcycle } \\
\text { on left lane } \\
(\%)\end{array}$} & \multirow{2}{*}{$\begin{array}{l}\text { Type of } \\
\text { ESS for } \\
\text { motor } \\
\text { cycle }\end{array}$} \\
\hline No & Name & Size & Approach & $\begin{array}{l}\text { Number and } \\
\text { width of lane }\end{array}$ & & & \\
\hline 1 & $\begin{array}{l}\text { Lingkar Selatan - Otto } \\
\text { Iskandar Dinata }\end{array}$ & Large & North & $\begin{array}{c}3: 3.6 \mathrm{~m}, 3.5 \mathrm{~m}, \\
3.5 \mathrm{~m}\end{array}$ & 60 & 80.12 & $\mathbf{P}$ \\
\hline 2 & Dipatiukur - Siliwangi & Large & North & $\begin{array}{c}3: 3.5 \mathrm{~m}, 3.5 \mathrm{~m}, \\
3.5 \mathrm{~m}\end{array}$ & 42 & 54.18 & Square \\
\hline 3 & $\begin{array}{l}\text { RE.Martadinata - } \\
\text { Ir.H.Juanda }\end{array}$ & Medium & North & $2: 3.5 \mathrm{~m}, 3.5 \mathrm{~m}$ & 36 & 65.90 & $\mathbf{P}$ \\
\hline 4 & $\begin{array}{l}\text { Lingkar Selatan - } \\
\text { Sriwijaya }\end{array}$ & Medium & West & $\begin{array}{c}3: 3.6 \mathrm{~m}, 3.5 \mathrm{~m}, \\
3.5 \mathrm{~m}\end{array}$ & 52 & 54.57 & Square \\
\hline
\end{tabular}

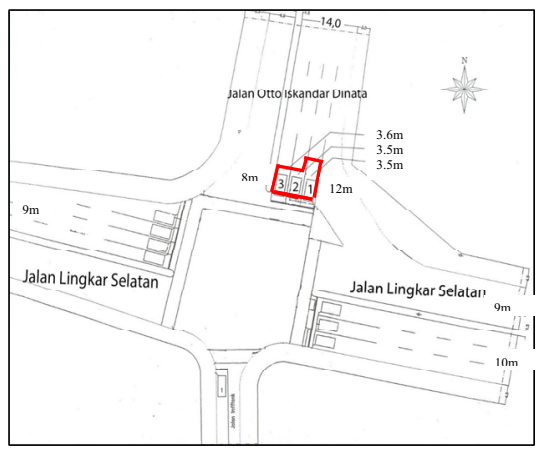

Fig. 9. Lingkar Selatan-Otto Iskandar Dinata large intersection in Bandung $[2,6]$

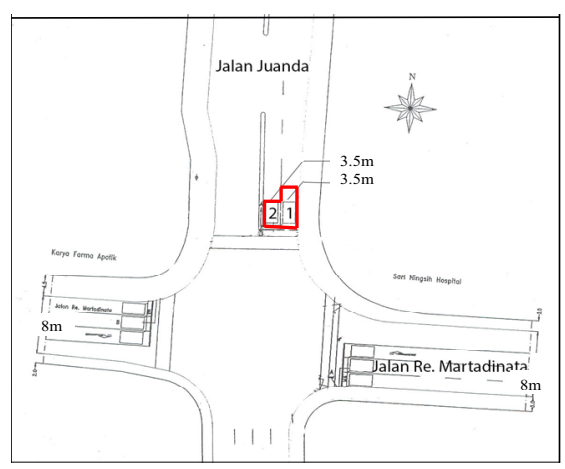

Fig. 11. RE.Martadinata-Ir.H.Juanda medium intersection in Bandung $[2,6]$

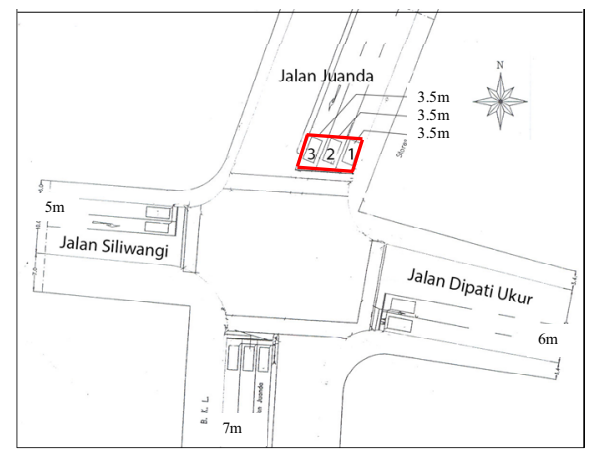

Fig. 10. Dipatiukur-Siliwangi large intersection in Bandung [2, 6]

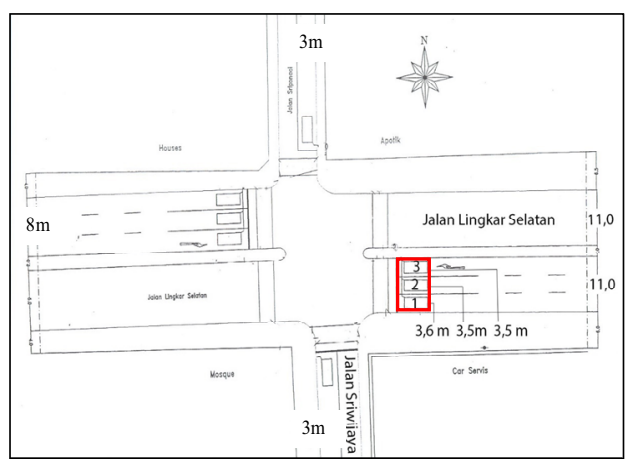

Fig. 12. Lingkar Selatan-Sriwijaya medium intersection in Bandung $[2,6]$ 


\subsection{Evaluation of implemented ESS for motorcycle}

Evaluation is going to conduct on implemented ESS for motorcycle in Bandung, Indonesia. 9 most congested signalized intersections of 39 signalized intersections that have already implemented ESS for motorcycle are evaluated. Criteria of evaluation are proportion of motorcycle on left lane (\%), capacity of ESS for motorcycle of all lanes (N1), and number of motorcycle stop during red time period (N2).

Furthermore, based on proportion of motorcycle on left lane (\%), existing type of ESS is evaluated, whether still square type or need to change to $\mathrm{P}$ type. Moreover, based on capacity of ESS for motorcycle of all lanes (N1) and number of motorcycle stop during red time period (N2) then effectiveness is determined by divide N2 with N1 in percentage. Fields data and evaluation of the 9 signalized intersections are presented in Table 2 [7].

Table 2. Evaluation of implemented ESS for motorcycle.

\begin{tabular}{|c|c|c|c|c|c|c|c|c|}
\hline \multicolumn{3}{|c|}{ Signalized Intersection } & \multicolumn{4}{|c|}{ Existing condition of ESS for motorcycle [7] } & \multirow[b]{2}{*}{$\begin{array}{c}\text { ESS type } \\
\text { evaluation } \\
*)\end{array}$} & \multirow{2}{*}{$\begin{array}{c}\text { Effectiveness } \\
\text { (N2/N1)x100\% } \\
\leq \mathbf{5 0 \%} \rightarrow \text { Low } \\
\mathbf{5 1} \%-79 \% \\
\rightarrow \text { Moderate } \\
\geq \mathbf{8 0} \% \rightarrow \text { High }\end{array}$} \\
\hline $\begin{array}{l}\mathbf{N} \\
\mathbf{0}\end{array}$ & Name & $\begin{array}{c}\text { Number of } \\
\text { leg } \\
\text { intersection } \\
\text { with ESS }\end{array}$ & Type & $\begin{array}{c}\text { Proportion } \\
\text { of } \\
\text { motorcycle } \\
\text { on left lane } \\
(\%)\end{array}$ & $\begin{array}{c}\text { Capacity } \\
\text { of all lanes } \\
\text {-N1 } \\
\text { (motorcycle) }\end{array}$ & $\begin{array}{l}\text { Number of } \\
\text { motorcycle } \\
\text { stop during } \\
\text { red time } \\
\text { period } \mathrm{N} 2\end{array}$ & & \\
\hline 1 & $\begin{array}{l}\text { Jendral Sudirman - } \\
\text { Otto Iskandar Dinata }\end{array}$ & $\begin{array}{l}1 \text { with } 2 \\
\text { lanes }\end{array}$ & Square & 52.30 & 92 & 80 & Square & 89 \\
\hline 2 & $\begin{array}{c}\text { Jendral Sudirman - } \\
\text { Jamika }\end{array}$ & $\begin{array}{c}2 \text { with } 2 \\
\text { lanes }\end{array}$ & Square & $47.10 ; 54.70$ & $46 ; 37$ & $24 ; 22$ & Square & $52.2 ; 59.5$ \\
\hline 3 & Jamika - Peta & $\begin{array}{l}1 \text { with } 3 \\
\text { lanes }\end{array}$ & Square & 54.70 & 70 & 47 & Square & 67.10 \\
\hline 4 & $\begin{array}{c}\text { Soekarno Hatta - Kiara } \\
\text { Condong }\end{array}$ & $\begin{array}{l}3 \text { with } 3 \\
\text { lanes }\end{array}$ & Square & $\begin{array}{c}48.20 ; 67.90 \\
57.40\end{array}$ & $116 ; 70 ; 46$ & $95 ; 69 ; 36$ & Square & $\begin{array}{c}81.90 ; 98.60 \\
78.30\end{array}$ \\
\hline 5 & $\begin{array}{c}\text { Soekarno Hatta - Buah } \\
\text { Batu }\end{array}$ & $\begin{array}{l}2 \text { with } 2 \\
\text { lanes }\end{array}$ & Square & $52.60 ; 59.60$ & $46 ; 56$ & $34 ; 52$ & $\mathrm{P}$ & $73.90 ; 92.9$ \\
\hline 6 & Soekarno Hatta - Kopo & $\begin{array}{l}1 \text { with } 2 \\
\text { lanes }\end{array}$ & Square & 43.30 & 46 & 45 & Square & 97.80 \\
\hline 7 & Lembong - Tamblong & $\begin{array}{l}1 \text { with } 2 \\
\text { lanes }\end{array}$ & Square & 49.80 & 46 & 46 & Square & 100 \\
\hline 8 & Tamblong - Naripan & $\begin{array}{l}1 \text { with } 3 \\
\text { lanes }\end{array}$ & Square & 66.50 & 70 & 62 & Square & 88.60 \\
\hline 9 & Veteran - Sunda & $\begin{array}{l}2 \text { with } 3 \\
\text { lanes }\end{array}$ & Square & $65.90 ; 50.80$ & $56 ; 37$ & $54 ; 33$ & Square & $96.40 ; 89.20$ \\
\hline
\end{tabular}

\subsection{Analysis of implementation of ESS for motorcycle}

Table 1 shows that 2 of 4 signalized intersections need Square type of motorcycle and 2 other need $\mathrm{P}$ type. Furthermore, although the 2 intersection only need Square type, but proportion of motorcycle on left lane (\%) is high i.e. $54.18 \%$ and $54.57 \%$. regular monitoring is needed to collect newest field data of increasing number of motorcycle during red time period. So that $\mathrm{P}$ type of ESS for motorcycle can be implemented soon. This is important because not changing Square type to $\mathrm{P}$ type on time as needed, can cause many motorcycle stop among cars that can block traffic flow and increase traffic congestion.

Table 2 shows that based on existing condition, effectiveness of using ESS for motorcycle is between moderate and high (52.2\%-100\%). Although ESS for motorcycle occupy space of other vehicles (disadvantage), but motorcycles located on exclusive area that will not block traffic flow and can reduce traffic congestion (advantages). This condition indicated that ESS for motorcycle in the city is needed and also need to be monitor regularly and consistently 


\section{Recommendation}

Based on existing conditions, recommendations that can be provided are as follow:

- Revised manual of ESS for motorcycle in Indonesia so that calculation and implementation also involve lanes with lane width less than $3.5 \mathrm{~m}$. This is important because number of motorcycle stop on lanes with lane width less than $3.5 \mathrm{~m}$ during red time period, in the city are, is high.

- Further studies are evaluation whether traffic parameter at intersection for example queue length, number of queue, and number of stops are better or not after implementation of ESS for motorcycle and also relationship between signalized intersection capacity and traffic congestion before and after implementation of ESS for motorcycle.

- Socialization to the society regarding benefit of using ESS for motorcycle in reducing traffic congestion at signalized intersections and also in the city.

\section{Conclusion}

Innovation of ESS for motorcycle is specific for cities and urban areas with high proportion of motorcycle like Indonesia. Moderate to high effectiveness value i.e. $52.20 \%-100 \%$ indicated that ESS for motorcycle is needed. The most important thing is that benefit of the result study for Bandung, other large cities in Indonesia, and can be implemented to other cities in other developing countries that have similar traffic and geometric conditions.

\section{References}

[1] Road and Bridge Research and Development Centre, Guidance of Exclusive Stopping Space for Motorcycle, $4^{\text {th }}$ Designed, Ministry of Public Works, Republic of Indonesia (2012)

[2] Directorate General of Bina Jalan Kota, Indonesian Highway Capacity Manual 1997, Directorate General of Bina Marga, Ministry of Public Work, Republic of Indonesia, (1997)

[3] AWA Plessey, Bandung Area Traffic Control, Final System Design, Directorate General of Land Transport, Ministry of Communications, Republic of Indonesia, (1996)

[4] A.C. Sutandi, Advance Traffic Control Systems, Performance Evaluation in Developing Country, Lambert Academic Publishing, (2010)

[5] A.C. Sutandi, Evaluation of the impacts of VMS on traffic performance measure in an urban area in Indonesia, Civil Engineering Dimension, Journal of civil Engineering Science and Application, 10(1), 28 - 34 (2008)

[6] D.D. Siregar, Choosing Signalized Intersections in Bandung City that Need ESS, Thesis, Parahyangan Catholic University, Bandung, (2016)

[7] M. Cahyaningtyas, Evaluation of ESS Implementation at Intersections in Bandung, Thesis, Parahyangan Catholic University, Bandung, (2014) 